\title{
O enfrentamento e a sobrevivência ao Coronavírus também precisa ser uma questão feminista!
}

\author{
MARIANE DA SILVA PISANI \\ Universidade Fedral do Tocantins, Tocantinópolis, Tocantins, Brasil \\ mariane.pisani@uft.edu.br
}

DOI 10.11606/issn.2316-9133.v29i1p156-162

\begin{abstract}
Como antropóloga ${ }^{1}$ que sou me dou o direito de iniciar este texto a partir de uma observação etnográfica. No dia 23 de Março de 2020, foi publicado no jornal O Globo a matéria intitulada: "NASA usa experiência de astronautas para dar dicas de confinamento durante a pandemia de COVID-19". Esta trouxe aos leitores e às leitoras cinco habilidades desenvolvidas por astronautas da Agência Espacial dos Estados Unidos da América (NASA) para viver isolamentos em períodos prolongados de tempo. A saber: comunicação, liderança, cuidados pessoais, cuidados do coletivo e vivência em grupo (O GLOBO, 2020).

A reportagem em questão foi replicada em diversas redes sociais de grupos de WhatsApp, atualmente nosso principal meio de comunicação e contato com amigos, amigas e familiares. Acompanhei algumas reações ao material veiculado:

"Existe criança na estação espacial? Não, não é mesmo!? Então essas dicas não me servem para nada!"

"Eu devo seguir essas dicas antes ou depois de lavar, passar, cozinhar e arrumar toda a casa?”.
\end{abstract}

Essas reações partiram, em sua grande maioria, de mulheres. Embora homens e mulheres estejam em reclusão neste momento - podendo, portanto dividir as tarefas domésticas e os cuidados com filhos - coube às mulheres desvelar - mais uma vez! - uma clássica questão dos debates feministas: mulheres arcam com o acúmulo e com a sobrecarga de tarefas no ambiente familiar. É preciso lembrar que com a sobrecarga o cansaço físico, emocional e mental aparecem e enfraquecem o sistema imunológico nos deixando sujeitas, portanto, às diversas infecções e doenças, inclusive a COVID-19.

\footnotetext{
${ }^{1}$ Texto originalmente publicado, em 03 de Maio de 2020, no Boletim Ciêntistas Sociais e o Coronavírus pela Associação Nacional de Pós-Graduação e Pesquisa em Ciênicas Sociais (ANPOCS). Para esta publicação o material sofreu pequenas alterações e algumas atualizações.
} 
Para além da iniquidade referente à divisão dos trabalhos domésticos, o Coronavirus nos obriga a evidenciar outras situações nas quais as relações de gênero apontam para inúmeras desigualdades entre homens e mulheres. Nesse sentido, uma série de reportagens on-line vem sendo veiculadas em diversos jornais de circulação nacional e internacional. O site Centre for Feminist Foreign Policy ${ }^{2}$ (Centro de Política Feminista estrangeira/do exterior, em tradução livre) fez um compilado daquelas que podem ser consideradas as mais expressivas. É sobre estas reportagens, disponíveis no site em questão, que escrevo agora minha reflexão. Quando necessário, trarei outras que - embora não disponíveis neste repositório - também nos ajudam a pensar a temática.

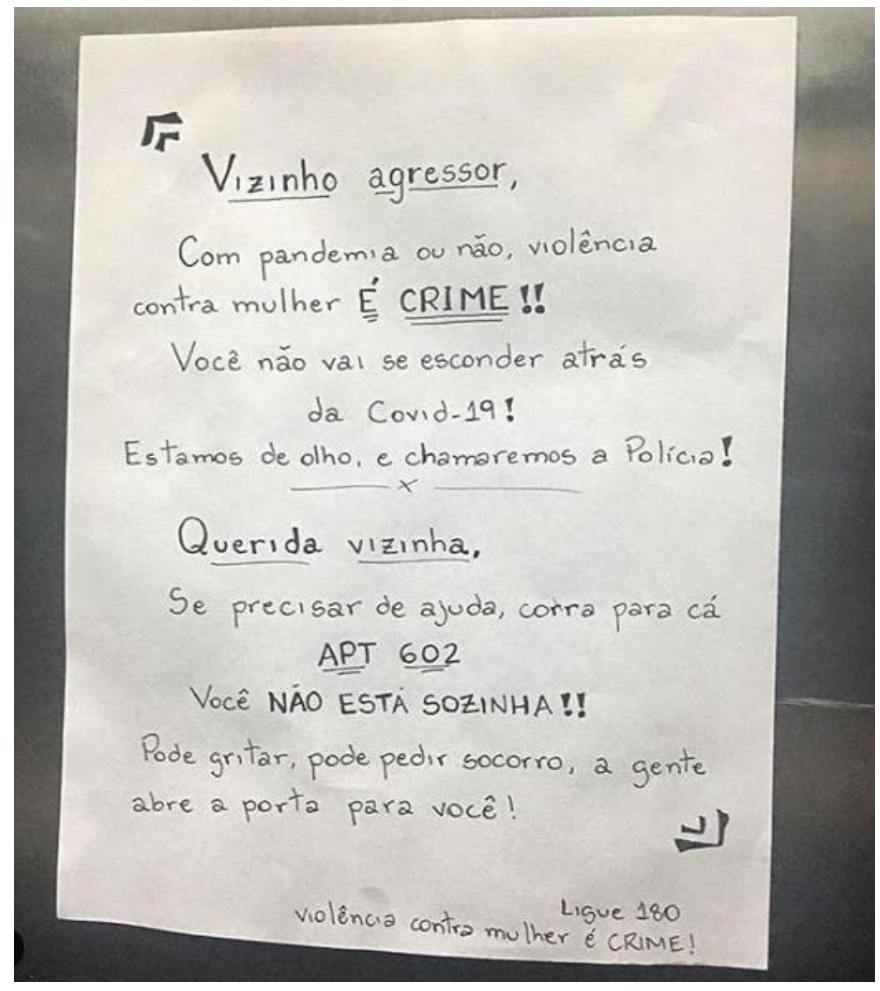

Figura 1. Bilhete denúncia. Imagem retirada do Instagram @oquenaonosdisseram

Ainda falando sobre as relações de gênero estabelecidas e vivenciadas no âmbito doméstico, vem sendo notificado em diversos países uma crescente onda de violência física e sexual contra as mulheres. Países como China, França e Reino Unido já anunciaram que as medidas de quarentena impostas em todo o mundo, associadas ao uso indiscriminado de álcool e das dificuldades financeiras - que surgem a partir da impossibilidade de trabalhar - propiciam o desenvolvimento de comportamentos coercitivos, controladores e violentos por parte dos agressores (O ESTADO DE SÃO PAULO, 2020). O distanciamento social medida também imposta para contenção do Coronavirus - faz com que muitas mulheres em situação de violência doméstica não tenham como procurar redes de apoio e atendimento.

\footnotetext{
2 Para conhecer, acesse o link: https://centreforfeministforeignpolicy.org/
} 
Na França, por exemplo, a ministra da Igualdade de Gêneros, Marlene Schiappa, apontou no dia 30 de Março de 2020, que os abusos domésticos reportados à polícia subiram $36 \%$ em Paris, capital, e 32\% no resto do país. Dois casos de Feminicídio foram reportados durante o período de reclusão na sociedade francesa (REUTERS, 2020). Já no Brasil, no dia 31 de Março de 2020, o site do Senado Federal divulgou que os estados Rio de Janeiro, Santa Catarina, Paraná e Goiás já apresentam - durante o período de quarentena - um aumento de 9\% nas ligações de denúncia através do número 180 (Central de Atendimento à Mulher) (AGÊNCIA SENADO, 2020). Surgem campanhas de combate e enfretamento à violência contra mulher; é o caso do Tribunal de Justiça da Bahia (TJBA) que divulgou em seu site oficial e redes sociais o seguinte slogan: "Quarentena sim! Violência não!”.

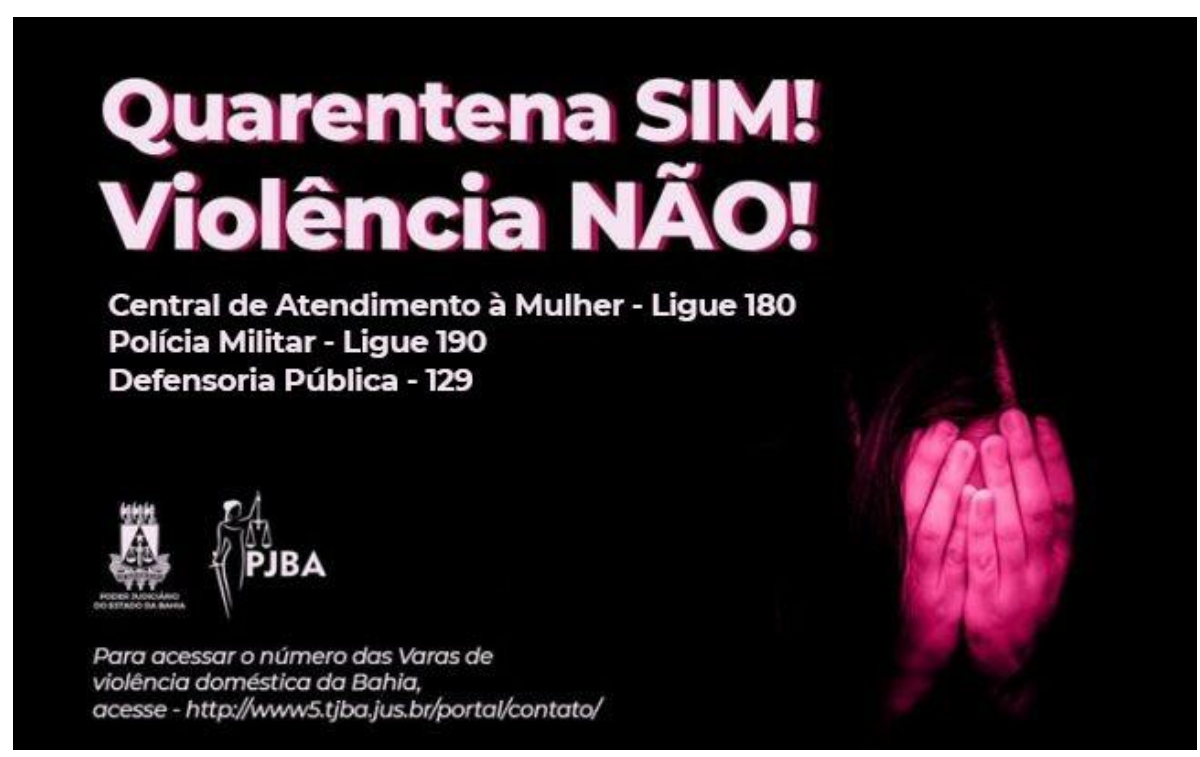

Figura 2. Campanha do Tribunal de Justiça da Bahia: Quarenta, sim! Violência, NÃO! Fonte: Tribunal de Justiça da Bahia, 2020.

Ainda neste sentido, o Ministério da Mulher, da Família e dos Direitos Humanos divulgou no dia 14 de Abril de 2020, uma cartilha intitulada "Mulheres na Covid-19”. Os principais temas abordados neste material foram questões relativa à Saúde, Enfrentamento à Violência e Mercado de Trabalho. Na parte que traz questões sobre o enfretamento à violência a cartilha preconiza que duas coisas são importantes para conter a violência contra as mulheres nesse momento de pandemia: informação e atendimento. Sobre a informação frisa-se a importância de ligar ao 180 para denunciar casos de violência; caso a mulher em situação de violência resida fora do Brasil - mas seja brasileira - o documento também oferece uma extensa lista de telefones que recebem ligações para atender esta demanda específica. Um ponto inovador que merece destaque é a criação do aplicativo para celular chamado "Proteja Brasil" que também aceita denuncias contra mulheres e crianças. 
A cartilha apresenta ainda os horários de funcionamento, o que são e como contactar cada uma das organizações a seguir: Casa da Mulher Brasileira ${ }^{3}$, Centro de Referência de Atendimento à Mulher em Situação de Violência ${ }^{4}$, Serviços de Saúde Especializados de Atendimento à Violência Sexual ${ }^{5}$, Casas Abrigo ${ }^{6}$, Defensorias Públicas Especializadas/Núcleos Especializados no acolhimento e atendimento às mulheres vítimas de violência doméstica e familiar, Delegacias Especializadas de Atendimento à Mulher, Patrulhas e Rondas Maria Da Penha ${ }^{7}$, Juizados Especializados de Violência Doméstica e Familiar contra a Mulher, Promotorias Especializadas em Violência Doméstica e Familiar contra a Mulher.

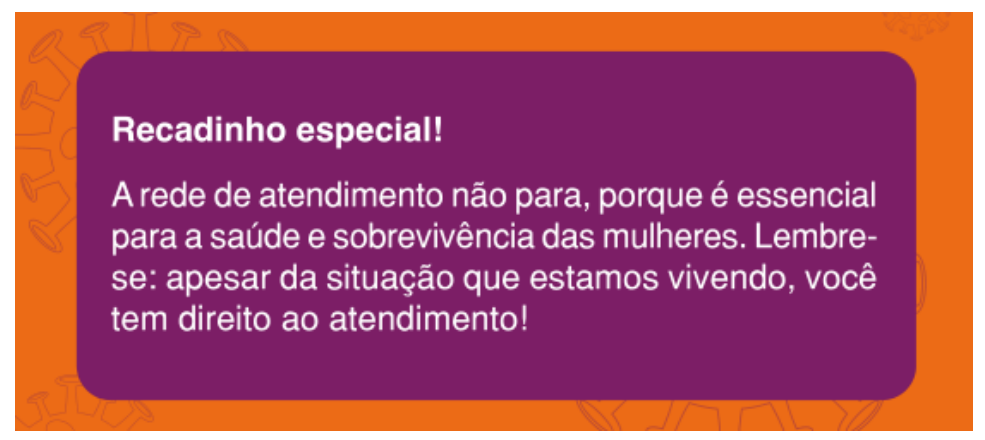

Figura 3. Imagem retirada da Cartilha "Mulheres e a COVID-19. Fonte: Ministério das Mulheres, da Familia e dos Direitos Humanos (2020).

A produção e a divulgação desta cartilha, que traz o levantamento de todos os órgãos supracitados que buscam mitigar a violência contra mulher brasileira, nos mostra que - de alguma maneira - o Governo Federal e seu Ministério das Mulheres, da Familia e dos Direitos Humanos mostram-se atento às novas demandas que surgem durante $o$ enfretamento da COVID-19, bem como ao aumento da violência contra mulher neste período.

\footnotetext{
${ }^{3}$ Local que possui atendimento humanizado e integrado às mulheres em situação de violência. Atualmente temos a Casa da Mulher Brasileira nas cidades Campo Grande, São Luis, Curitiba, Fortaleza, São Paulo e Boa Vista.

${ }^{4}$ Espaços públicos que prestam acolhimento, acompanhamento psicossocial e orientação jurídica às mulheres em situação de violência.

${ }^{5}$ Que conta com uma equipe multidisciplinar composta por psicólogos, assistentes sociais, enfermeiros e médicos. Nesses espaços mulheres que tenham sofrido violência sexual recebem, em caráter de urgência, a PEP (Profilaxia Pós-Exposição) ao HIV.

${ }^{6}$ Locais seguros que oferecem abrigo protegido e integral às mulheres em situação de violência doméstica e familiar, sob risco de morte iminente, e a seus filhos. Para ser encaminhada para uma das Casas-Abrigo, a mulher em situação de violência precisa ser encaminhada por algum desses órgãos: Delegacia Especializada de Atendimento à Mulher, Centros de Referência/Especializados de Atendimento à Mulher ou Centros de Referência de Assistência Social.

${ }^{7}$ Geralmente realizada pela Guarda Municipal de cada cidade.
} 
Outro ponto que precisa ser destacado nesta reflexão diz respeito aqueles que estão prestando os serviços básicos de saúde e que estão atualmente na linha de frente no combate à COVID-19, logo mais vulneráveis à exposição ao vírus. A reportagem veiculada no jornal The New York Times, no dia 12 de Março de 2020, intitulada Why Women May Face a Greater Risk of Catching Coronavirus (Por que as mulheres podem enfrentar um risco maior de pegar Coronavírus, em tradução livre), nos alerta que o mercado de trabalho da saúde ainda é bastante marcado por papéis de gênero (GUPTA, 2020).

Atualmente, em escala global, as mulheres representam cerca de $70 \%$ da força de trabalho na área de saúde. Ou seja, são as médicas, enfermeiras, técnicas de enfermagem e agentes de saúde que estarão mais expostas ao novo vírus. Segundo a médica norteamericana Celine Gounder, especialista em doenças infecciosas da Faculdade de Medicina da Universidade de New York, as enfermeiras estão mais propensas à exposição ao Coronavirus do que médicos ou médicas, afinal são as enfermeiras e técnicas de enfermagem que estão em contato direto com as secreções que facilitam o contágio e disseminação da COVID-19 como, por exemplo, saliva, catarro e fezes. Além disso, no que diz respeito aos cuidados com doentes no âmbito doméstico, mais uma vez as mulheres em todo o mundo têm maior probabilidade de assumir esta tarefa caso alguém na família seja acometido/a pelo Coronavirus.

A mesma reportagem ainda pontua outra questão: as epidemias e as pandemias geram impactos econômicos desproporcionais entre homens e mulheres. São as mulheres que ocupam grande parte dos trabalhos informais e de meio período. Esses trabalhos, por sua vez, são os primeiros a serem descartados ou mesmo dispensados em períodos de incerteza econômica. No Brasil, o Ministério do Trabalho (MT) veiculou em Nota Técnica 04/2020, no dia 17 de Março de 2020, que trabalhadoras e trabalhadores domésticos devem ser dispensados de seus trabalhos sem que, contudo, percam sua remuneração e/ou direitos trabalhistas $^{8}$. Apesar da nota do MT, não é um consenso entre "patrões" e "patroas" que usufruem dos serviços desta categoria (NUNES, 2020). É de conhecimento geral que em nosso país a primeira vítima fatal no estado do Rio de Janeiro foi uma trabalhadora doméstica, de 63 anos, que contraiu o vírus de sua empregadora que, apesar de apresentar os sintomas característicos da doença, recusou-se a dispensá-la (MELO, 2020). Por fim, ainda sobre esta questão, é comum que em tempos de pandemia muitas mulheres desistam de seus empregos e/ou mesmo de suas fontes de renda para ficar em casa cuidando de suas famílias. Muitas delas enfrentarão, futuramente, dificuldades para voltar ao mercado de trabalho, mesmo depois de findado o período de pandemia.

Pouco ainda se fala no Brasil da paralisação ou suspensão de serviços essenciais para a manutenção da vida sexual e reprodutiva das mulheres em tempos de pandemia COVID19. Contudo, o artigo científico recentemente publicado por Julia Houssein - Editora Chefe da Revista Sexual and Reproductive Health Matters -, aponta algumas dificuldades que

\footnotetext{
${ }^{8}$ Para ler a Nota Técnica do Ministério do Trabalho, acesse o link clicando aqui.
} 
poderemos enfrentar futuramente. Para Houssein, com a emergência dos atendimentos direcionados ao COVID-19 surgirão desequilíbrios na prestação de serviços de saúde das mulheres como, por exemplo, interrupção dos serviços essenciais de rotina como, por exemplo, os exames de Papanicolau e os acompanhamentos pré-natal. Para a autora, os serviços de saúde materna e reprodutiva podem ser os mais atingidos uma vez que as com instalações médicas estarão limitadas às áreas de isolamento da COVID-19. Mulheres em trabalho de parto e bebês recém-nascidos deverão enfrentar escassez e falta de infraestrutura no atendimento hospitalar (HOUSSEIN, 2020) o que, por sua vez, pode ocasionar altos índices de mortalidade materna e infantil.

Para finalizar esta reflexão é preciso que realizamos uma pergunta crucial: Quem está tomando as principais decisões sobre respostas à pandemia COVID-19?

É de conhecimento de todos que os líderes mundiais são majoritariamente homens, e esses homens tendem - vias de regra - a representar uma elite e um grupo social dominante em escala global. Da mesma forma, na publicação Global Health Report ${ }^{9}$ do ano de 2019 ,constata-se que $72 \%$ dos chefes executivos em saúde global são homens. Contudo é urgente adotar uma postura feminista ativa e eficaz para o enfrentamento e para sobrevivência frente ao Coronavírus. Ou seja, é preciso que as parcelas mais vulneráveis de nossa sociedade - mulheres negras, mulheres mais pobres, trabalhadoras informais - sejam levadas em consideração no enfretamento à pandemia COVID-19.

\section{Referências Bibliográficas}

AGÊNCIA SENADO. (2020). Coronavírus: senadores alertam para violência contra a mulher durante isolamento. Agência Senado (online). Brasília, ano 2020,31-março. Disponível em: https://www12.senado.leg.br/noticias/materias/2020/03/31/coronavi rus-senadores-alertam-para-violencia-contra-a-mulher-durante-isolamento. Acesso: 16/abr/2020.

GUPTA, Alisha Haridasani. (2020). Why Women May Face a Greater Risk of Catching Coronavirus. The New York Times (online). Nova York, ano 2020, 12-março. Disponível em: https://www.nytimes.com/2020/03/12/us/women-coronavirusgreater-risk.html. Acesso em: 16 abr. 2020.

HUSSEIN, Julia. (2020). Editorial: COVID-19: What implications for sexual and reproductive health and rights globally? In: Sexual and Reproductive Health Matters, vol.28.n.1 p.1-3.

MELO, Maria Luisa de. (2020). Primeira Vítima do RJ era doméstica e pegou coranavirus da patroa no Leblon. Portal Uol Notícias, ano 2020, 19-março. Disponível em: https://noticias.uol.com.br/saude/ultimas-noticias/redacao/2020/03/19/primeira-

\footnotetext{
${ }^{9}$ Para ler o relatório, acesse o link clicando aqui.
} 
vitima-do-rj-era-domestica-e-pegou-coronavirus-da-patroa.htm. Acesso em: 16 abr. 2020

NUNES, Aurélio. (2020). Domésticas defendem direito à quarentena remunerada e dividem patrões. Portal Uol Notícias (omline), ano 2020, 29-março. Disponível em: https://noticias.uol.com.br/saude/ultimas-noticias/redacao/2020/03/29/domesticasdefendem-direito-a-quarentena-remunerada-e-dividem-patroes.htm. Acesso em: 16 abr. 2020.

O ESTADO DE SÃO PAULO. (2020). França colocará vítimas de violência doméstica em hotéis após aumento de casos durante quarentena. O Estado de São Paulo (online), ano 2020, 30-março. Disponível em: https://internacional.estadao.com.br/noticias/g eral,franca-colocara-vitimas-de-violencia-domestica-em-hoteis-apos-aumento-decasos-durante-quarentena,70003254121. Acesso em: 16 abr. 2020.

O GLOBO. (2020). Nasa usa experiência de astronautas para dar dicas de confinamento durante a pandemia de Covid-19. O Globo (online). Ano 2020, 23-março. Disponível em: https://oglobo.globo.com/sociedade/coronavirus-servico/nasa-usa-experiencia-deastronautas-para-dar-dicas-de-confinamento-durante-pandemia-de-covid-1924322874. Acesso em: 16 abr. 2020.

REUTERS. (2020). França colocará vítimas de violência doméstica em hotéis após salto em números de casos. Portal G1 Notícias (online), ano 2020, 31-março. Disponível em: https://g1.globo.com/mundo/noticia/2020/03/30/franca-colocara-vitimas-deviolencia-domestica-em-hoteis-apos-salto-em-numeros-de-casos.ghtml. Acesso em: 16 abr. 2020.

\section{Mariane Pisani}

É professora da Universidade Federal do Tocantins, campus Tocantinópolis. É doutora em Antropologia Social (USP), mestra em Antropologia Social (UFSC) e graduada em Ciências Sociais (UFSC). É pesquisadora do Laboratório do Núcleo de Antropologia Urbana (LabNAU/USP) e do Grupo de Pesquisa em Antropologia Social e Intersecionalidades (ANTROPOS/UFT).

\section{Recebido em 20/04/2020 Aceito para publicação em 10/06/2020}

